\title{
The adsorption of phosphate using a magnesia-pullulan composite: kinetics, equilibrium, and column tests
}

\author{
Yuanyao $\mathrm{Ye}^{1,2} \cdot \mathrm{Jie}^{\mathrm{Jiao}}{ }^{3} \cdot$ Dejun $\mathrm{Kang}^{4} \cdot$ Wei Jiang ${ }^{1} \cdot$ Jianxiong Kang ${ }^{1} \cdot$ Huu Hao $\mathrm{Ngo}^{2} \cdot$ Wenshan Guo $^{2} \cdot$ Yiwen \\ Liu $^{2}$
}

\begin{abstract}
A magnesia-pullulan (MgOP) composite has been developed to remove phosphate from a synthetic solution. In the present study, the removal of phosphate by $\mathrm{MgOP}$ was evaluated in both a batch and dynamic system. The batch experiments investigated the initial $\mathrm{pH}$ effect on the phosphate removal efficiency from $\mathrm{pH} 3$ to 12 and the effect of co-existing anions. In addition, the adsorption isotherms, thermodynamics, and kinetics were also investigated. The results from the batch experiments indicate that MgOP has encouraging performance for the adsorption of phosphate, while the initial $\mathrm{pH}$ value (3-12) had a negligible influence on the phosphate removal efficiency. Analysis of the adsorption thermodynamics demonstrated that the phosphate removal process was endothermic and spontaneous. Investigations into the dynamics of the phosphate removal process were carried out using a fixed bed of $\mathrm{MgOP}$, and the resulting breakthrough curves were used to describe the column phosphate adsorption process at various bed masses, volumetric flow rates, influent phosphate concentrations, reaction temperatures, and inlet $\mathrm{pH}$ values. The results suggest that the adsorption of phosphate on $\mathrm{MgOP}$ was improved using an increased bed mass, while the reaction temperature did not significantly affect the performance of the MgOP bed during the phosphate removal process. Furthermore, higher influent phosphate concentrations were beneficial towards increasing the column adsorption capacity for phosphate. Several mathematic models, including the Adams-Bohart, Wolboska, Yoon-Nelson, and Thomas models, were employed to fit the fixed-bed data. In addition, the effluent concentration of magnesium ions was measured and the regeneration of $\mathrm{MgOP}$ investigated.
\end{abstract}

Keywords Phosphate $\cdot$ Adsorption $\cdot$ Breakthrough curve $\cdot$ Column experiments $\cdot$ Regeneration

Electronic supplementary material The online version of this article (https://doi.org/10.1007/s11356-019-04858-z) contains supplementary material, which is available to authorized users.

\section{Wei Jiang}

jiangwei0707@hust.edu.cn

1 School of Environmental Science and Engineering, Huazhong University of Science and Technology, No. 1037 Luoyu Road, Wuhan 430074, People's Republic of China

2 Centre for Technology in Water and Wastewater, School of Civil and Environmental Engineering, University of Technology Sydney, Sydney, NSW 2007, Australia

3 Wisdri City Environmental Protection Engineering Co., Ltd., Wuhan, People's Republic of China

4 Department of Municipal Engineering, College of Civil Engineering, Fuzhou University, Fuzhou 350116, People's Republic of China

\section{Introduction}

Phosphorus plays an irreplaceable role in the growth of all organisms found in the ecosystem. Naturally, it exists in a large variety of chemical forms, in which phosphate ions $\left(\mathrm{PO}_{4}{ }^{3-}\right)$ are the main form. Excessive use of phosphatebased fertilizers and improper wastewater treatment result in an enrichment of phosphate in water bodies ( $\mathrm{Li}$ et al. 2017; Zhang et al. 2018). It is believed that the presence of an excessive amount of phosphate contributes to eutrophication, which promotes the growth of harmful algae and thereby leads to an inadequate amount of dissolved oxygen in water (Lin et al. 2017; Mor et al. 2016; Wan et al. 2017). Consequently, the death of aquatic life occurs, and the quality of the aquatic environment deteriorates. More importantly, eutrophication has a serious impact on the use of water for different purposes, and to date, this issue has yet to be solved. Therefore, it is essential to eliminate an excessive amount of phosphate from wastewater to ensure that the phosphate content is below the limit of discharge standard. 
Currently, the main techniques used for phosphate removal include chemical precipitation, biological processes, membrane hybrid systems, and ion exchange and adsorption (Huang et al. 2017a; Ye et al. 2017; Ye et al. 2016b; Zhu et al. 2013). However, biological phosphate removal is energy-intensive, and a large area is involved in the process. Moreover, strict control of the operating conditions may increase the difficulty in its feasibility. As for chemical precipitation, it is expensive as reverse osmosis, ion exchange, and electrodialysis. In contrast to the other methods used for phosphate removal, adsorption is effective and economic due to its flexible design and operation, high stability and efficiency, and low cost (Ashekuzzaman and Jiang 2017; Jiang et al. 2016; Lee et al. 2017; Wang et al. 2012; Zhang et al. 2009). In addition, adsorption is preferable for the recovery of phosphate at low concentration and can be applied in undeveloped countries (Loganathan et al. 2014; Nguyen et al. 2015). To date, many materials have been developed for the phosphate removal (Huang et al. 2017b; Liu et al. 2018; Ye et al. 2017). Due to the strong specific affinity between phosphate ions and metal sites, oxides and hydroxides of metals and their modifications have been widely used to remove phosphate from wastewater (Hu et al. 2017; Shi et al. 2019; Tang et al. 2019; $\mathrm{Xu}$ et al. 2017).

However, the studies on the phosphate removal via $\mathrm{Mg}$ containing materials are few despite the fact that several researches exhibited the potential of $\mathrm{Mg}$-based material for phosphate adsorption (Lan et al. 2018; Tang et al. 2018; Tang et al. 2017). It is well known that the struvite $\left(\mathrm{MgNH}_{4} \mathrm{PO}_{4} \cdot 6 \mathrm{H}_{2} \mathrm{O}\right)$ could be obtained if the concentrations and solution are favorable (Ye et al. 2017), which also facilitates the simultaneous removal/recovery of phosphate and ammonium. Thus, the application of Mg-based material for removing phosphate from wastewater has the opportunity to achieve struvite or soil with a certain amount of struvite. Reportedly, the modified magnesia adsorbent has high potential for the phosphate removal (Kumar and Viswanathan 2017). This may be attributed to the chemical properties of the magnesium ions being similar to the Lewis acid. In this case, they lose the electrons in the outer layer, and thereby, the metal ions can easily combine with phosphate. Besides, Kang et al. (2011) found that the integration of pullulan (biodegradable extracellular water-soluble microbial polysaccharide) with magnesia could enlarge the specific surface area when compared with the original magnesia, which enhanced the phosphate removal. In the present study, pullulan was mixed with magnesia to prepare a magnesia-pullulan composite (MgOP). Since MgOP could also effectively remove fluoride from wastewater (Kang et al. 2011), this undoubtedly increases the application potential of $\mathrm{MgOP}$ in the treatment of wastewater contaminated by phosphate.

In general, the objectives of this study were to explore the phosphate removal by $\mathrm{MgOP}$ in a single-adsorbate system using both batch and continuous systems. In batch mode, the phosphate removal efficiency was explored under various initial solution $\mathrm{pH}$ values and the presence of co-existing anions, respectively. Detailed studies regarding the adsorption kinetics and thermodynamics were conducted as well as the adsorption isotherm experiments. For the continuous system, the phosphate removal process with MgOP was performed using a fixed-bed column and the breakthrough curves for phosphate adsorption were applied to identify the removal efficiency of MgOP (Ye et al. 2018b). In this scenario, the parameters that influenced the breakthrough curves including the bed mass, flow rate, influent phosphate concentration and inlet $\mathrm{pH}$ value were evaluated. Moreover, mathematical models were exploited to assess the performance of the fixed bed to remove phosphate from an aqueous solution. It should be noted here that the column tests of the phosphate adsorption on $\mathrm{MgOP}$ can offer basic information for scaling up the MgOP application from laboratory scale to pilot/plant scale and thereby facilitate the commercial application of $\mathrm{MgOP}$ in treating wastewater contaminated by phosphate. Apart from this, the regeneration of $\mathrm{MgOP}$ was also studied as well as the stability of MgOP.

\section{Materials and methods}

\section{Preparation of MgOP}

The synthesis of MgOP was achieved as previously described (Kang et al. 2011). Pullulan was provided by Shandong Freda Biotechnology Co., Ltd., Linxi, China. Specifically, $8 \mathrm{~g}$ of $\mathrm{MgO}$ was dissolved in $600 \mathrm{~mL}$ of deionized water, and then $12 \mathrm{~g}$ of pullulan was introduced into the mixture. The resulting solution was stirred at room temperature for $24 \mathrm{~h}$ and subsequently heated in an oven at $105^{\circ} \mathrm{C}$ for $12 \mathrm{~h}$. The resulting solid was calcined for $2 \mathrm{~h}$ at $450{ }^{\circ} \mathrm{C}$, and the resulting composite (i.e., $\mathrm{MgOP}$ ) was then allowed to cool to room temperature and sieved to obtain 0.074-mm-diameter particles. Finally, the sieved MgOP was stored in a dry bag. Apart from this, the specific surface area of original $\mathrm{MgO}$ and $\mathrm{MgOP}$ was 7.59 and $32.90 \mathrm{~m}^{2} / \mathrm{g}$, respectively (Kang et al. 2011), which indicates that $\mathrm{MgOP}$ has higher defluoridation capacity when compared with $\mathrm{MgO}$.

\section{Analytical and characterization methods}

A $50 \mathrm{mg} \cdot \mathrm{P} / \mathrm{L}$ stock solution of phosphate was obtained using potassium dihydrogen phosphate. The stock solution was diluted to prepare the working phosphate solutions. To determine the phosphate content in the treated water, an ammonium molybdate spectrophotometric method was applied (GuoMei 2006). The initial $\mathrm{pH}$ values of the solution were adjusted using $1.0 \mathrm{~mol} / \mathrm{L}$ sodium hydroxide $(\mathrm{NaOH})$ and $1.0 \mathrm{~mol} / \mathrm{L}$ 
hydrochloric acid $(\mathrm{HCl})$ solutions and confirmed using a $\mathrm{pH}$ meter. The effluent magnesium concentrations were examined using an atomic absorption spectrophotometer (Willis 1961).

\section{Batch phosphate adsorption}

The initial $\mathrm{pH}$ effect on the phosphate removal process was studied in 50-mL tubes containing $\mathrm{MgOP}$ and the phosphate solution. According to our previous study (Ye et al. 2016a), the $\mathrm{MgOP}$ concentration was $1.2 \mathrm{~g} / \mathrm{L}$. The experiment was performed on a thermostatic shaker at $150 \mathrm{rpm}$ at $25{ }^{\circ} \mathrm{C}$. The effect of co-existing anions on the phosphate removal process was explored. In addition, the adsorption kinetic experiments were also explored as was the temperature effect (i.e., adsorption isotherms and thermodynamics). Before analyzing the aqueous samples, they were filtered using a $0.45-\mu \mathrm{m}$ membrane filter.

All the experiments were duplicated under the same conditions and the data examined through an analysis of the standard deviations. The amount of phosphate adsorbed by $\mathrm{MgOP}$ was calculated using Eq. (1).

$q_{t}=\frac{V\left(C_{0}-C_{t}\right)}{m}$

where $q_{t}(\mathrm{mg} / \mathrm{g})$ represents the adsorption capacity of phosphate at reaction time $(t)(\mathrm{min}), m$ is the dry weight of $\mathrm{MgOP}$, $V$ is the volume of the phosphate solution, and $C_{0}$ and $C_{t}$ are the initial phosphate concentration and residual phosphate concentration at $t$, respectively.

\section{Continuous phosphate adsorption}

An organic glass column (internal diameter $=4 \mathrm{~cm}$ and height $=20 \mathrm{~cm}$ ) was applied in the fixed-bed studies with downward flow. A certain amount of MgOP was packed into the column. Moreover, a peristaltic pump was used to control the flow rate in a given experiment. Glass wool $(\sim 10 \mathrm{~cm})$ was packed into the bottom of the cylinder to prevent MgOP outflow. The effluent samples were analyzed at different reaction times. The performance of the fixed bed of MgOP used for the phosphate removal process was evaluated using the breakthrough curves obtained under different operation conditions, such as bed mass $(2,4$, and $6 \mathrm{~g}$, which were corresponding to the bed height of $2.6,5.2$, and $7.8 \mathrm{~cm}$, respectively), initial phosphate concentration $(1,5,10$, and $20 \mathrm{mg} / \mathrm{L}$ ), flow velocity (8 16 and $24 \mathrm{~mL} / \mathrm{min}$ ), reaction temperature $\left(25,35\right.$, and $\left.45{ }^{\circ} \mathrm{C}\right)$, and inlet $\mathrm{pH}$ $(5,7$, and 9). In addition, several mathematical models, including the Adams-Bohart, Wolboska, Thomas, and Yoon-Nelson models, were applied to simulate the experimental data. It should be noted that the continuous phosphate removal process using $\mathrm{MgOP}$ was carried out in duplicate and each column was conducted in parallel during the experiments. The column adsorption capacity for phosphate was determined using Eq. (2).

$q_{e}=\frac{Q}{1000 m} \int_{t=0}^{t=t_{\text {total }}}\left(C_{0}-C_{t}\right) d t$

where $C_{t}$ is the residual phosphate concentration in the effluent, $C_{0}(\mathrm{mg} / \mathrm{L})$ represents the initial phosphate concentration, $t_{\text {total }}(\mathrm{h})$ is the exhaustion time in which $C_{t} /$ $C_{0}$ reached $0.9, Q(\mathrm{~mL} / \mathrm{min})$ is the flow velocity, $m(\mathrm{~g})$ is the dry weight of MgOP in the column, and $q_{e}(\mathrm{mg} /$ g) is the column capacity at the exhaustion point. The breakthrough time $\left(t_{b}\right)$ is the time where $C_{t} / C_{0}$ reached 0.1 .

Apart from this, the length of the fixed bed where adsorption of solutes takes place is defined as mass transfer zone (MTZ), and its calculation was shown in Eq. (3) (Chatterjee et al. 2017; Vieira et al. 2019).

$\mathrm{MTZ}=h\left(1-\frac{t_{b}}{t_{\text {total }}}\right)$

where $h(\mathrm{~cm})$ is the column height.

\section{MgOP regeneration}

In the regeneration experiment, $0.1 \mathrm{~mol} / \mathrm{L}$ solutions of $\mathrm{HCl}$, $\mathrm{NaOH}$, sodium chloride $(\mathrm{NaCl})$, sodium carbonate $\left(\mathrm{Na}_{2} \mathrm{CO}_{3}\right)$, citric acid $\left(\mathrm{C}_{6} \mathrm{H}_{8} \mathrm{O}_{7}\right)$ and sodium citrate $\left(\mathrm{Na}_{3} \mathrm{C}_{6} \mathrm{H}_{5} \mathrm{O}_{7}\right)$, and deionized water were employed as the desorbing agents. The phosphate-loaded $\mathrm{MgOP}$ was obtained using a mixture of the phosphate solution $(10 \mathrm{mg} / \mathrm{L})$ and $\mathrm{MgOP}(1.2 \mathrm{~g} / \mathrm{L})$ for $24 \mathrm{~h}$ at $25{ }^{\circ} \mathrm{C}$. After drying, the phosphate-loaded MgOP was immersed in the elution solution and then continuously stirred for $24 \mathrm{~h}$ at $25^{\circ} \mathrm{C}$. Notably, the $\mathrm{pH}$ of all the solvents was above 3 to initiate the dissolution of $\mathrm{MgOP}$. After desorption, the dried phosphate-desorbed $\mathrm{MgOP}(1.2 \mathrm{~g} / \mathrm{L})$ was mixed with the phosphate solution $(10 \mathrm{mg} / \mathrm{L})$, which was shaken for $24 \mathrm{~h}$ at $25^{\circ} \mathrm{C}$. The regeneration efficiency (RE) was calculated using Eq. (4).

$\mathrm{RE}=\frac{q_{r}}{q_{0}} \times 100 \%$

where $q_{r}(\mathrm{mg} / \mathrm{g})$ is the adsorption capacity of the regenerated $\mathrm{MgOP}$ and $q_{0}(\mathrm{mg} / \mathrm{g})$ is the adsorption capacity of the original MgOP sample. In addition, the calcination of the used MgOP under inert conditions was also carried out to examine the $\mathrm{MgOP}$ regeneration process. The resulting solid $(1.2 \mathrm{~g} / \mathrm{L})$ was mixed with the phosphate solution $(10 \mathrm{mg} / \mathrm{L})$ as discussed above to obtain the regeneration efficiency. The adsorption/ regeneration process was repeated six times using the same $\mathrm{MgOP}$ sample. 


\section{Results and discussion}

\section{Batch phosphate adsorption}

\section{The effect of the initial pH value}

The $\mathrm{pH}$ value controls the dissociation equilibrium of phosphate ions, as shown in Eqs. (5)-(7) (Chitrakar et al. 2006).

$$
\begin{aligned}
& \mathrm{H}_{3} \mathrm{PO}_{4} \rightleftharpoons \mathrm{H}^{+}+\mathrm{H}_{2} \mathrm{PO}_{4}{ }^{-}\left(p K_{a}=2.16\right) \\
& \mathrm{H}_{2} \mathrm{PO}_{4}{ }^{-} \rightleftharpoons \mathrm{H}^{+}+\mathrm{HPO}_{4}{ }^{2-}\left(p K_{a}=7.2\right) \\
& \mathrm{HPO}_{4}{ }^{2-} \rightleftharpoons \mathrm{H}^{+}+\mathrm{PO}_{4}{ }^{3-}\left(p K_{a}=12.35\right)
\end{aligned}
$$

The phosphate removal process using MgOP was studied at different initial $\mathrm{pH}$ values (3-12) with $1.2 \mathrm{~g} / \mathrm{L}$ of $\mathrm{MgOP}$ and a $10 \mathrm{mg} / \mathrm{L}$ phosphate solution. From Fig. 1, the adsorption capacity of $\mathrm{MgOP}$ for phosphate was high over a wide $\mathrm{pH}$ range (3-12). According to the assumption of surface complexation, the MgOP surface has many active hydroxyl groups. In this scenario, protonation and deprotonation will occur on the $\mathrm{MgOP}$ surface under acidic and alkaline environments, respectively (Eqs. (8) and (9)) (Hu et al. 2016; Huang et al. 2015).

Protonation $(\mathrm{pH}<7): \equiv \mathrm{SOH}+\mathrm{H}_{(\mathrm{s})}^{+} \leftrightarrow \equiv \mathrm{SOH}_{2}^{+}$

$$
\text { Deprotonation }(\mathrm{pH}>7): \equiv \mathrm{SOH} \leftrightarrow \equiv \mathrm{SO}^{-}+\mathrm{H}_{(\mathrm{s})}^{+}
$$

where $\equiv \mathrm{SOH}, \equiv \mathrm{SOH}_{2}{ }^{+}$, and $\equiv \mathrm{SO}^{-}$represent neutral, positively charged, and negatively charged hydroxyl groups on the $\mathrm{MgOP}$ surface, respectively, and $\mathrm{H}^{+}(\mathrm{s})$ is the concentration of $\mathrm{H}^{+}$ions on the surface of $\mathrm{MgOP}$.

An acidic environment can result in the formation of a positively charged surface $\mathrm{MgOP}$ and $\mathrm{H}_{2} \mathrm{PO}_{4}{ }^{2-}$ as the

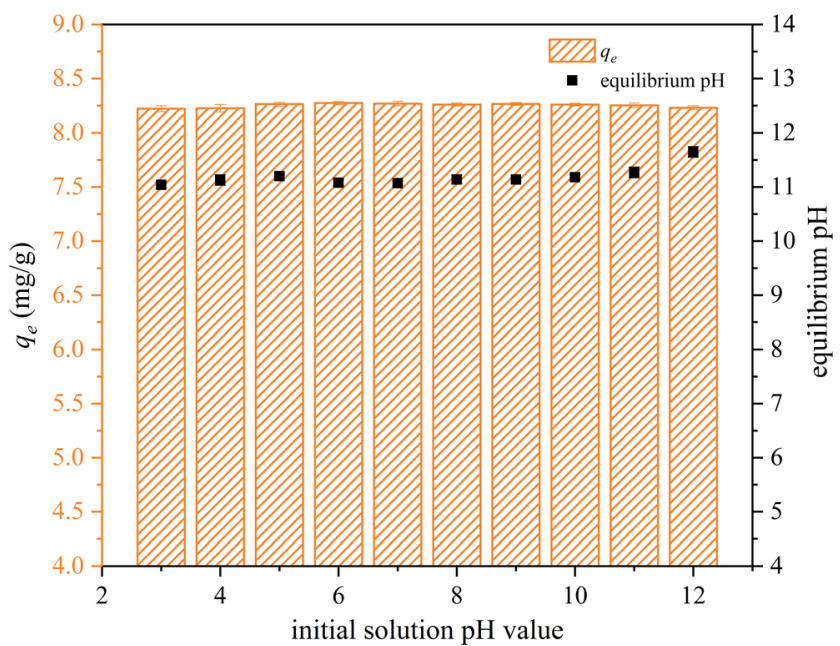

Fig. 1 The effect of the initial $\mathrm{pH}$ on the phosphate removal process using MgOP. Conditions: $\mathrm{MgOP}$ concentration $=1.2 \mathrm{~g} / \mathrm{L}$, contact time $=$ $100 \mathrm{~min}$, reaction temperature $\left(25^{\circ} \mathrm{C}\right)$, and initial phosphate concentration $=10 \mathrm{mg} / \mathrm{L}$ predominant species of phosphate. In this scenario, the phosphate removal process using $\mathrm{MgOP}$ was enhanced due to the electrostatic attraction between $\mathrm{H}_{2} \mathrm{PO}_{4}{ }^{2-}$ and the $\mathrm{MgOP}$ surface. Increasing the $\mathrm{pH}$ decreases the effect of electrostatic attraction because the MgOP surface is negatively charged, and electrostatic repulsion increasingly dominates the reaction between the $\mathrm{MgOP}$ surface and phosphate ions. In addition, an increased concentration of hydroxyl ions may negatively affect the phosphate removal process (Zhang et al. 2010) since there is a competition between the hydroxyl ions and phosphate ions for the hydroxyl groups on the MgOP surface. However, the experimental results show an opposite trend in which the phosphate removal efficiency was not significantly influenced upon increasing the initial $\mathrm{pH}$ from 7 to 12 . This may be attributed to the $\mathrm{pH}_{\mathrm{zpc}}$ value of $\mathrm{MgOP}$, standing at 10.7 (Kang et al. 2011). In this scenario, the case where the solution $\mathrm{pH}$ was less than the $\mathrm{pH}_{\mathrm{zpc}}$ may result in the electronic attraction between the MgOP surface and phosphate ions. Consequently, the effective phosphate adsorption via $\mathrm{MgOP}$ was obtained before solution $\mathrm{pH}$ reaching 10.7. Moreover, according to the study of Ye et al. (2018a), increasing pH may only affect the adsorption rate of phosphate and have negligible impacts on the total number of hydroxyl groups on the MgOP surface. In other words, the high adsorption capacity of MgOP for phosphate could also be achieved at solution $\mathrm{pH}$ over 10.7, and the equilibrated adsorption capacity of $\mathrm{MgOP}$ for phosphate was negligibly varied over a wide initial $\mathrm{pH}$ range (3-12). In addition, the equilibrated $\mathrm{pH}$ was stable in the range from 10.7 to 11.2. This may be ascribed to the ligand exchange observed between the phosphate ions and hydroxyl groups on the MgOP surface, which results in the equilibrium $\mathrm{pH}$ under alkaline conditions. Apart from this, MgOP prefers to adsorb $\mathrm{H}^{+}$ions than $\mathrm{OH}^{-}$ions (Ye et al. 2018a), which causes the $\mathrm{pH}$ elevation of treated phosphate solution. To sum up, our investigations on the $\mathrm{pH}$ effect suggest that $\mathrm{MgOP}$ is effective for phosphate removal from a wide range of wastewater/water sources.

\section{The effect of co-existing anions}

Since anions such as chloride, sulfate, bicarbonate, and nitrate often co-exist with phosphate in wastewater, these anions at different initial concentrations $(100-500 \mathrm{mg} / \mathrm{L})$ were added to the tubes used in our investigation, which contained $1.2 \mathrm{~g} / \mathrm{L}$ of $\mathrm{MgOP}$ and the $10 \mathrm{mg} / \mathrm{L}$ of phosphate solution, in order to evaluate the selectivity of $\mathrm{MgOP}$ for phosphate. The reactions were carried out for $100 \mathrm{~min}$. From Fig. 2, all the anions had an insignificant effect on the adsorption efficiency for phosphate. This was attributed to MgOP having a higher affinity for phosphate ions than the anions mentioned above. Furthermore, $\mathrm{H}_{2} \mathrm{PO}_{4}{ }^{2-}$ ions are the predominant form of phosphate ion found in the present study, and it has been reported that multivalent anions are more easily adsorbed when 


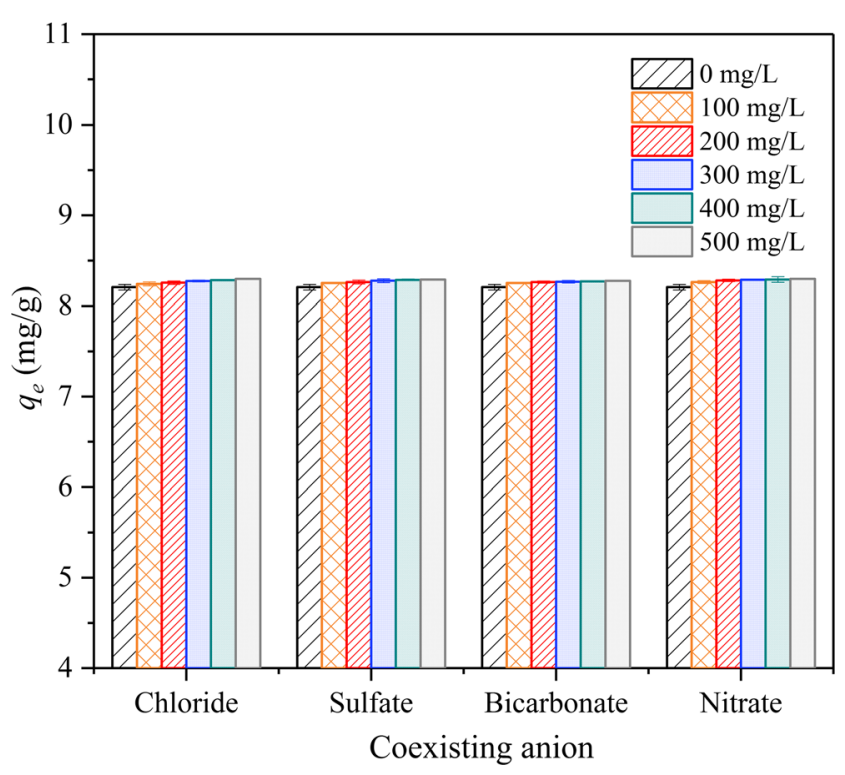

Fig. 2 The effect of co-existing anions on the phosphate removal process using MgOP. Conditions: $\mathrm{MgOP}$ concentration $=1.2 \mathrm{~g} / \mathrm{L}$, contact time $=$ $100 \mathrm{~min}$, reaction temperature $\left(25^{\circ} \mathrm{C}\right)$, and initial phosphate concentration $=10 \mathrm{mg} / \mathrm{L}$

compared with monovalent anions (Wan et al. 2012). Even though the addition of $\mathrm{HCO}_{3}{ }^{-}$increased the solution $\mathrm{pH}$ to some extent, this change had no notable impact on the adsorption of phosphate and a similar trend was observed to that found in the $\mathrm{pH}$ effect study.

\section{The mechanism for phosphate adsorption on MgOP}

As discussed above, the phosphate removal process using $\mathrm{MgOP}$ was endothermic and a chemisorption process (see the Supplementary Information). According to another study, the $\mathrm{pH}_{\mathrm{zpc}}$ of $\mathrm{MgOP}$ is 10.7 (Kang et al. 2011). In addition, the analysis of the Fourier transform infrared spectroscopy (FTIR) spectra recorded in our previous study (Ye et al. 2016a) and the results derived from the $\mathrm{pH}$ effect study further imply the adsorption mechanism of phosphate on $\mathrm{MgOP}$ :

1. When solution $\mathrm{pH}$ is less than the $\mathrm{pH}_{\mathrm{zpc}}$ of $\mathrm{MgOP}$ (10.7), protonation of the hydroxyl groups leads to the formation of a positively charged surface on the MgOP. In this scenario, the adsorption of phosphate was enhanced because the electrostatic attraction increased the transfer of phosphate ions (negatively charged ions) to the positively charged surface of $\mathrm{MgOP}$. Therefore, electrostatic interaction and ligand exchange are the main mechanisms of the phosphate removal using MgOP during the adsorption process at $\mathrm{pH}<7.0$.

2. When solution $\mathrm{pH}$ is over the $\mathrm{pH}_{\mathrm{zpc}}$ of $\mathrm{MgOP}$ (10.7), a negatively charged surface on the $\mathrm{MgOP}$ is formed due to the increasing $\mathrm{OH}^{-}$content. Theoretically, the weakened electrostatic attraction decreases the phosphate adsorption on $\mathrm{MgOP}$. However, the high adsorption capacity of $\mathrm{MgOP}$ for phosphate was also observed under alkaline conditions because high $\mathrm{pH}$ only affects the adsorption rate of phosphate through changing the surface charge of $\mathrm{MgOP}$ whereas the number of hydroxyl groups on the $\mathrm{MgOP}$ surface is insignificantly influenced as well as the equilibrated adsorption capacity of $\mathrm{MgOP}$ for phosphate.

In addition, the FTIR spectra studied in our previous study (Ye et al. 2016a) showed the presence of hydrogen bonding between phosphate ion and hydroxyl group (Arai and Sparks 2001; Belelli et al. 2014; Uzunova and Mikosch 2016), which is also involved in the mechanism for phosphate adsorption on $\mathrm{MgOP}$. Since the energy of adsorption in H-bonding is lower than that in the ligand exchange process (Loganathan et al. 2013), it is apparent that the ligand exchange process may be the main mechanism for phosphate removal using $\mathrm{MgOP}$.

Based on Eqs. (5)-(7), the $\mathrm{H}_{2} \mathrm{PO}_{4}{ }^{-}$and $\mathrm{HPO}_{4}{ }^{2-}$ ions dominate the species of phosphate ions over the $\mathrm{pH}$ range of 3-12. Therefore, the mechanism for phosphate removal using MgOP includes ligand exchange (Eqs. (10) and (11)) and $\mathrm{H}-$ bonding with phosphate ions (Eqs. (12) and (13)).

Ligand exchange : $\equiv \mathrm{S}-\mathrm{OH}+\mathrm{H}_{2} \mathrm{PO}_{4}^{-} \leftrightarrow \mathrm{S}-\mathrm{OPO}_{3} \mathrm{H}_{2}$

$$
+\mathrm{OH}^{-}
$$

$\equiv \mathrm{S}-\mathrm{OH}+\mathrm{HPO}_{4}^{2-} \leftrightarrow \mathrm{S}-\mathrm{OPO}_{3} \mathrm{H}^{-}+\mathrm{OH}^{-}$

$\mathrm{H}$-bonding : $\equiv \mathrm{S}-\mathrm{OH}+\mathrm{H}_{2} \mathrm{PO}_{4}^{-} \leftrightarrow \mathrm{S}-\mathrm{OH} \cdots \mathrm{OPO}_{3} \mathrm{H}_{2}$

$\equiv \mathrm{S}-\mathrm{OH}+\mathrm{HPO}_{4}^{2-} \leftrightarrow \mathrm{S}-\mathrm{OH} \cdots \mathrm{OPO}_{3} \mathrm{H}^{-}$

\section{Dynamic phosphate adsorption}

\section{The effect of the bed mass}

The effects of various bed masses $(2,4$, and $6 \mathrm{~g})$ on the phosphate adsorption process at a flow velocity of $16 \mathrm{~mL} / \mathrm{min}$ and influent phosphate concentration of $10 \mathrm{mg} / \mathrm{L}$ are shown in Fig. 3. An increased amount of MgOP results in a smaller slope in the breakthrough curve. The breakthrough time and exhaustion time both increase at a high bed mass. For example, increasing the bed mass from 2 to $6 \mathrm{~g}$ causes the breakthrough time to increase from 0.5 to $4.7 \mathrm{~h}$. This is attributed to the higher bed mass possessing a longer contact time between the phosphate ions and MgOP. Moreover, increasing the bed mass may provide more hydroxyl groups available for phosphate removal and an increase in the height of the mass transfer zone. As a result, the column adsorption capacity for phosphate increases from $3.39 \mathrm{mg} / \mathrm{g}$ observed for a bed mass of $2 \mathrm{~g}$ to $11.53 \mathrm{mg} / \mathrm{g}$ observed for a bed mass of $6 \mathrm{~g}$. Other studies have also reported a similar trend (Chowdhury and Saha 2013; 


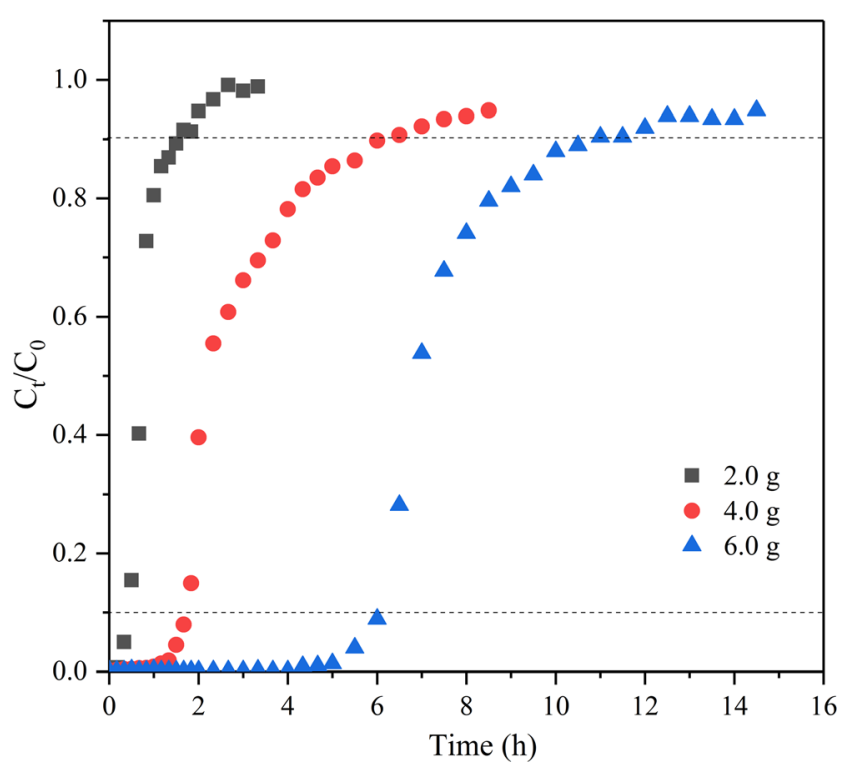

Fig. 3 The effect of the bed mass on the breakthrough curves observed for the phosphate removal process using MgOP. Conditions: bed mass = 2-6 g, volumetric flow rate $=16 \mathrm{~mL} / \mathrm{min}$, influent phosphate concentration $=10 \mathrm{mg} / \mathrm{L}$, and room temperature $\left(25^{\circ} \mathrm{C}\right)$

Guo et al. 2013; Ye et al. 2018b). However, an increased bed pressure drop may result from an excessive bed mass (Du et al. 2018), which can seriously affect the phosphate adsorption process. Therefore, a bed mass of $4 \mathrm{~g}$ was used in the following dynamic experiments.

\section{The effect of the flow velocity}

The breakthrough curves at different volumetric flow rates $(8$, 16 , and $24 \mathrm{~mL} / \mathrm{min}$ ) using a bed mass of $4 \mathrm{~g}$ and inlet phosphate concentration of $10 \mathrm{mg} / \mathrm{L}$ are depicted in Fig. 4. Sharper breakthrough curves were observed at a higher flow rate, which was related to the mass transfer process. In this scenario, the breakthrough time decreased from 3.3 to $0.7 \mathrm{~h}$ upon increasing the flow rate from 8 to $24 \mathrm{~mL} / \mathrm{min}$. The decreased pattern is similar to the exhaustion time because a higher volumetric flow rate increases the mass transfer rate, so the amount of phosphate ions adsorbed per unit bed mass increased and the time taken for $\mathrm{MgOP}$ to reach saturation is decreased. Moreover, increasing the flow rate may accelerate the downward flow of phosphate ions, and their residence time in the column is thereby decreased. As a consequence, the column adsorption capacity of phosphate theoretically decreases upon increasing the flow rate. However, the adsorption capacity of phosphate increases from 5.72 to $6.88 \mathrm{mg} / \mathrm{g}$ as the flow rate is varied from 8 to $16 \mathrm{~mL} / \mathrm{min}$. The possible reason for this is that a higher flow rate may result in more phosphate flowing into the column with time (Xia and Wang 2014). Hence, the phosphate removal process can be improved by appropriately increasing flow rate, and a flow rate of $16 \mathrm{~mL} / \mathrm{min}$ was thus used in the subsequent experiments.

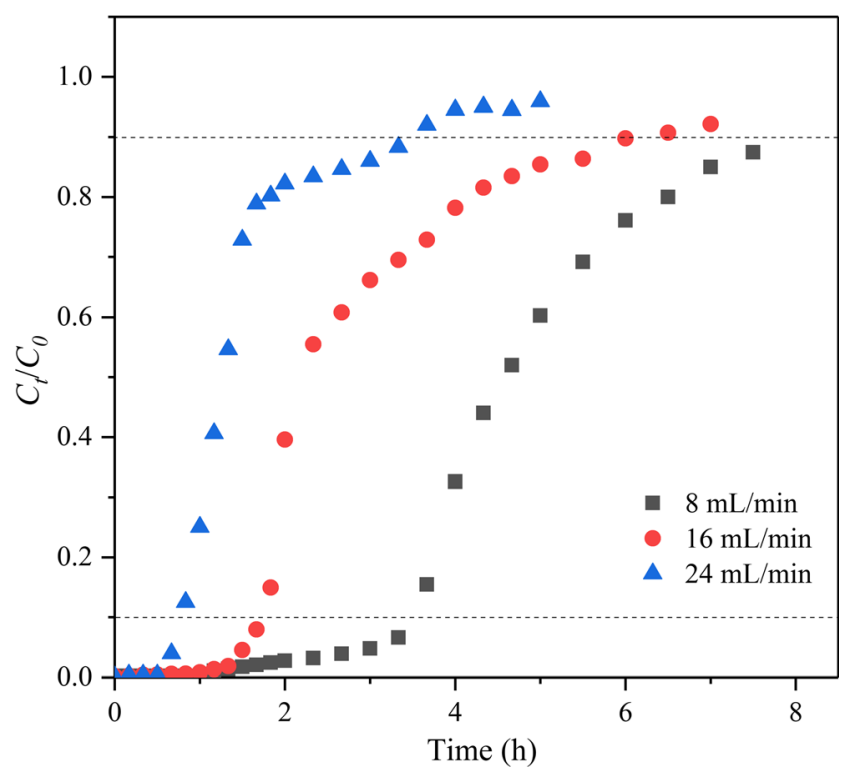

Fig. 4 The effect of the volumetric flow rate on the breakthrough curves observed for the phosphate removal process using $\mathrm{MgOP}$. Conditions: bed mass $=4 \mathrm{~g}$, volumetric flow rate $=8-24 \mathrm{~mL} / \mathrm{min}$, influent phosphate concentration $=10 \mathrm{mg} / \mathrm{L}$, and room temperature $\left(25^{\circ} \mathrm{C}\right)$

\section{The effect of the influent phosphate concentration}

The breakthrough curves at different initial phosphate concentrations using a bed mass of $4 \mathrm{~g}$ and flow rate of $16 \mathrm{~mL} / \mathrm{min}$ are illustrated in Fig. 5. Increasing the inlet phosphate concentration can lead to a steeper breakthrough curve. In addition, the column adsorption capacity for phosphate ions increased from 2.68 to $9.57 \mathrm{mg} / \mathrm{g}$ as the influent phosphate

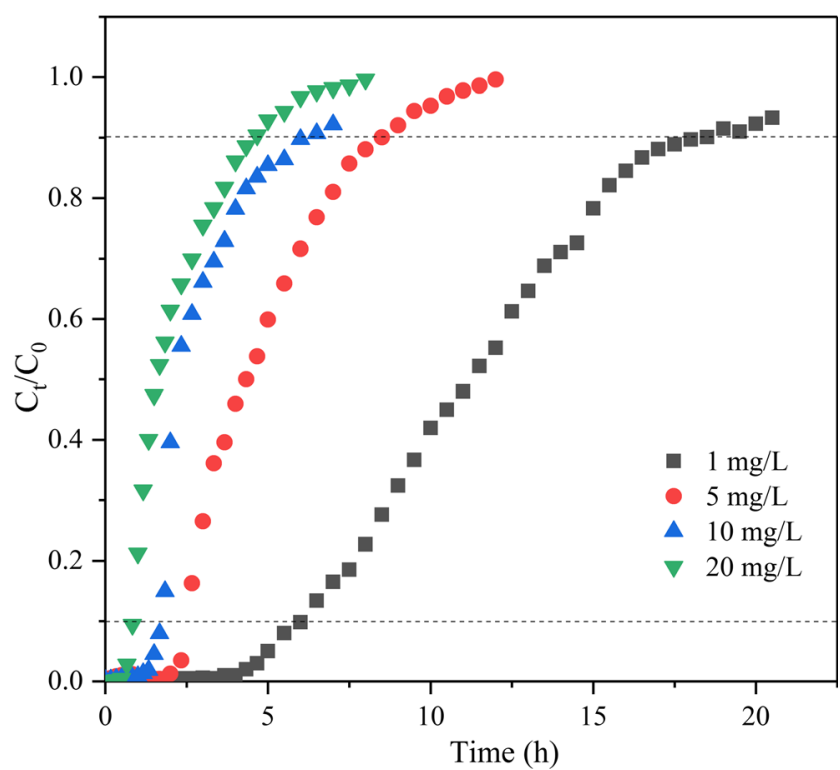

Fig. 5 The effect of the influent phosphate concentration on the breakthrough curves observed for the phosphate removal process using MgOP. Conditions: bed mass $=4 \mathrm{~g}$, volumetric flow rate $=16 \mathrm{~mL} / \mathrm{min}$, influent phosphate concentration $=1-20 \mathrm{mg} / \mathrm{L}$, and room temperature $\left(25^{\circ} \mathrm{C}\right)$ 
concentration was varied from 1 to $20 \mathrm{mg} / \mathrm{L}$. This can be ascribed to the higher driving force of mass transfer caused by the greater phosphate concentration gradient between the solution and $\mathrm{MgOP}$ surface. These findings also indicate that the fixed-bed adsorption process depends on the phosphate concentration (Muliwa et al. 2018; Nur et al. 2014; Shi et al. 2018). However, the breakthrough time for phosphate adsorption decreases from 11.2 observed for an influent phosphate concentration of $1 \mathrm{mg} / \mathrm{L}$ to $0.65 \mathrm{~h}$ observed for an influent phosphate concentration of $20 \mathrm{mg} / \mathrm{L}$. Similar changes were observed for the exhaustion time because a higher influent phosphate concentration may accelerate the adsorption saturation process, resulting in a decrease in the breakthrough and exhaustion time.

\section{The effect of the influent $\mathrm{pH}$ value}

The effect of the inlet $\mathrm{pH}(5,7$, and 9) on the breakthrough curves observed for the phosphate adsorption process using $\mathrm{MgOP}$ was explored. The experiments were performed using a bed mass of $4 \mathrm{~g}$, flow velocity of $16 \mathrm{~mL} / \mathrm{min}$, and initial phosphate concentration of $10 \mathrm{mg} / \mathrm{L}$ (Fig. 6). Theoretically, the column adsorption capacity for phosphate may be negligibly affected by increasing the initial $\mathrm{pH}$ from 5 to 7 because of the MgOP's $\mathrm{pH}_{\mathrm{zpc}}$ being 10.7 (Kang et al. 2011), as discussed in "The effect of the initial $\mathrm{pH}$ value" section. Indeed, the adsorption capacity for phosphate at the exhaustion time decreases from $6.76 \mathrm{mg} / \mathrm{g}$ at an initial $\mathrm{pH}$ of 5 to $5.56 \mathrm{mg} / \mathrm{g}$ at an initial $\mathrm{pH}$ of 7 , but the adsorption capacity increases to $7.31 \mathrm{mg} / \mathrm{g}$ at $\mathrm{pH}$ 9. The possible reason for this is

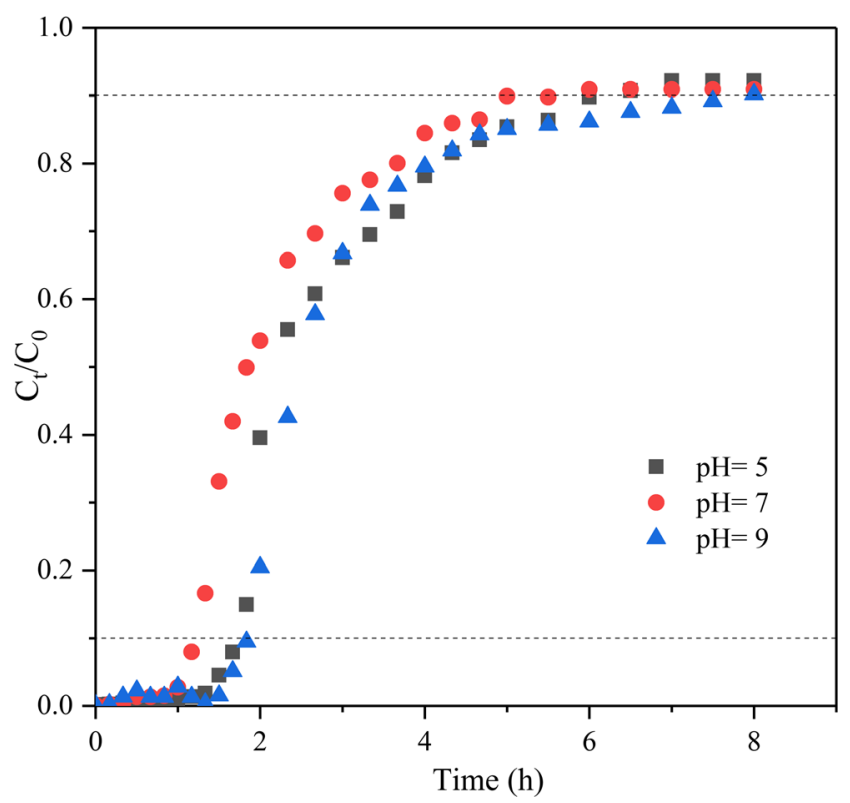

Fig. 6 The effect of the influent $\mathrm{pH}$ value on the breakthrough curves observed for the phosphate removal process using MgOP. Conditions: bed mass $=4 \mathrm{~g}$, volumetric flow rate $=16 \mathrm{~mL} / \mathrm{min}$, influent phosphate concentration $=10 \mathrm{mg} / \mathrm{L}$, and room temperature $\left(25^{\circ} \mathrm{C}\right)$ that increasing the $\mathrm{pH}$ may vary the adsorption rate of phosphate on MgOP (Ye et al. 2018a) and the breakthrough curves were thereby influenced as well as the column capacity at the exhaustion time. This is despite the fact that the total number of hydroxyl groups on the MgOP surface is insignificantly affected. In contrast, the batch experiments show that the phosphate ions are effectively removed from a synthetic aqueous solution over a wide range of $\mathrm{pH}(3-10)$. A possible explanation for this is that the variations in the initial solution $\mathrm{pH}$ may not significant impact on the equilibrated adsorption capacity of MgOP for phosphate (Ye et al. 2018a), as mentioned in "The effect of the initial $\mathrm{pH}$ value" section.

\section{Breakthrough curve models}

Predicting the parameters of a continuous fixed-bed column is important, not only for a laboratory-scale study, but also for industrial-scale processes. A breakthrough curve is the plot of the effluent and influent concentration ratios versus the running time, and its prediction can help to better understand the mechanism involved in the removal process and to predict any further changes that may occur under different operating conditions (Borba et al. 2006). In the present study, the column breakthrough curves observed for the phosphate removal process using MgOP were evaluated using mathematic models, including the Adams-Bohart, Wolboska, Thomas, and YoonNelson models.

\section{Adams-Bohart model and Wolborska model}

Bohart and Adams (1920) developed the Adams-Bohart model, which is based on the surface reaction rate theory and is always used to evaluate the initial part of breakthrough curves. In addition, the Adams-Bohart model assumes that the adsorption rate is proportional to both the adsorbate concentration and the remaining adsorption capacity of the adsorbent, and the equilibrium is not instantaneous. The Adams-Bohart model is given by Eq. (14).

$t=\frac{N_{0} Z}{C_{t} U_{0}}-\frac{1}{k_{\mathrm{AB}}} \operatorname{In}\left(\frac{C_{t}}{C_{0}}-1\right)$

where $k_{\mathrm{AB}}(\mathrm{L} /(\mathrm{mg} \min ))$ is the kinetic constant of the AdamsBohart model, $t$ ( $\mathrm{min}$ ) is the running time from the beginning to the end of breakthrough, $N_{0}$ is the column adsorption capacity estimated by the Adams-Bohart model, $Z(\mathrm{~cm})$ is the height of the column, and $U_{0}(\mathrm{~cm} / \mathrm{min})$ is the volumetric flow rate.

Apart from this, the Wolborska model is based on the mass transfer phenomenon for the inner diffusion mechanism at low concentrations. It is always used to describe the initial segment of the breakthrough curves (Wolborska 1989). The model is given by Eq. (15). 
$t=\frac{\operatorname{In} \frac{C_{t}}{C_{0}}}{\beta_{a} C_{0}} N_{0}+\frac{Z}{C_{0 U_{0}}} N_{0}$

where $\beta_{a}\left(\mathrm{~min}^{-1}\right)$ is the rate constant of the Wolborska model.

The Adams-Bohart model and Wolborska model can share the same the linear dependence ( $\operatorname{In} \frac{C_{t}}{C_{0}}$ vs. $t$ ). Hence, these two models may share the same plots. Moreover, the column adsorption capacities estimated by the Wolborska and AdamsBohart models are theoretically equal. As shown in Table 1, the values of $R^{2}$ range from 0.819 to 988 and indicate that the breakthrough curves can be predicted using the AdamsBohart model and Wolborska model with satisfactory results. The values of $k_{\mathrm{AB}}$ increase at a higher volumetric flow rate, which indicates that external mass transfer controls the initial part of the phosphate removal process (Aksu and Gönen 2004). Moreover, the values of $N_{0}$ increase upon increasing the influent phosphate concentration, as expected.

\section{Thomas model}

The present isotherm and kinetic studies indicate that the Langmuir isotherm and pseudo-second-order kinetic model have a good agreement with the phosphate removal process using $\mathrm{MgOP}$. The Thomas model assumes that the adsorption follows the second-order reversible reaction kinetics and the Langmuir isotherm with no axial diffusion (Thomas 1944). In addition, the column void fraction and physical properties of the adsorbent are also constant when the Thomas model is employed. The effects of intra-particle diffusion during the mass transfer process may be ignored as well as the external resistance effects while applying the Thomas model for the simulation. The Thomas model can be given by Eq. (16).

$t=\frac{q_{T} m}{Q C_{0}}+\frac{\operatorname{In}\left(\frac{C_{0}}{C_{e}}-1\right)}{k_{T} C_{0}}$

where $q_{T}(\mathrm{mg} / \mathrm{g})$ is the column adsorption capacity predicted by the Thomas model, $Q(\mathrm{~mL} / \mathrm{h})$ is the flow velocity, $k_{T}(\mathrm{~mL} /$ $\mathrm{h} / \mathrm{mg}$ ) is the kinetic rate constant of the Thomas model, and $m$ (g) is the bed mass.

The Thomas model can fit the breakthrough curves observed for the phosphate adsorption process using $\mathrm{MgOP}$ $\left(R^{2} 0.898-993\right)$. In addition, the adsorption capacities estimated by the Thomas model have a better agreement with the experimental values when compared with the AdamsBohart model and Wolborska model. The $k_{T}$ values depend on the flow rate, influent phosphate concentration, and bed mass. For example, the values of $k_{T}$ increase by increasing the flow rate, which is ascribed to the higher driving force caused by the greater flow rate. In contrast, changes in the influent $\mathrm{pH}$ values have a negligible effect on the $k_{T}$ values, which implies that the rate of mass transfer was not influenced by this factor.

\section{Yoon-Nelson model}

The Yoon-Nelson model can predict 50\% of the breakthrough time and is always employed to simulate the column data derived from a single-adsorbate system (Yoon and Nelson 1984). The model assumes that the rate of decrease in the probability of adsorption for each adsorbate molecule is proportional to the probability of adsorbate adsorption and the probability of adsorbate breakthrough on the adsorbent (Xu et al. 2013). More importantly, calculation of the YoonNelson model needs neither the properties of the adsorbate and adsorbent nor the column system's structure. The model can be described using Eq. (17).

$t=\tau+\operatorname{In}\left(\frac{C_{0}}{C_{t}}-1\right)^{k_{\mathrm{YN}}}$

where $k_{\mathrm{YN}}\left(\mathrm{min}^{-1}\right)$ is the rate constant of the Yoon-Nelson model and $\tau(\mathrm{min})$ is the time where $50 \%$ of the adsorbate is adsorbed. Therefore, the adsorbent will become completely exhausted at $t=2 \tau$.

The results of the Yoon-Nelson model shown in Table 1 show that the $R^{2}$ values are $>0.92$, which ensures the validity of the model and its high goodness of fit for the fixed-bed adsorption process of phosphate. The higher values of $\tau$ suggest the longer breakthrough time and slow adsorption saturation. However, the values of $\tau$ evaluated using the YoonNelson model are smaller than the experimental $\tau$ values since the model does not consider the properties of $\mathrm{MgOP}$ and the parameters of the fixed-bed column. Besides, $k_{\mathrm{YN}}$ increased at a higher volumetric flow rate since the adsorption of phosphate was enhanced by increasing the flow velocity (Fathy et al. 2017).

\section{Phosphate regeneration of $\mathrm{MgOP}$}

For the removal of phosphate via adsorption, it is the most important to regenerate the MgOP composite without significantly affecting its original adsorption capacity. In this case, the $\mathrm{MgOP}$ can be reused and thereby increase the economic feasibility of the phosphate adsorption process. As shown in Fig. 7, the regeneration efficiency of the phosphate-adsorbed $\mathrm{MgOP}$ was around 50\% using studied solvents. Among them, deionized water, in theory, has no effects on the regeneration efficiency, but the results showed an opposite trend in which application of deionized water could also obtain the regeneration rate of the phosphate-loaded $\mathrm{MgOP}(\sim 50 \%)$. The kinetic results showed that phosphate-loaded $\mathrm{MgOP}$, which was obtained at an initial phosphate concentration of $10 \mathrm{mg} / \mathrm{L}$, may not reach saturation. As a result, the phosphate-loaded MgOP 


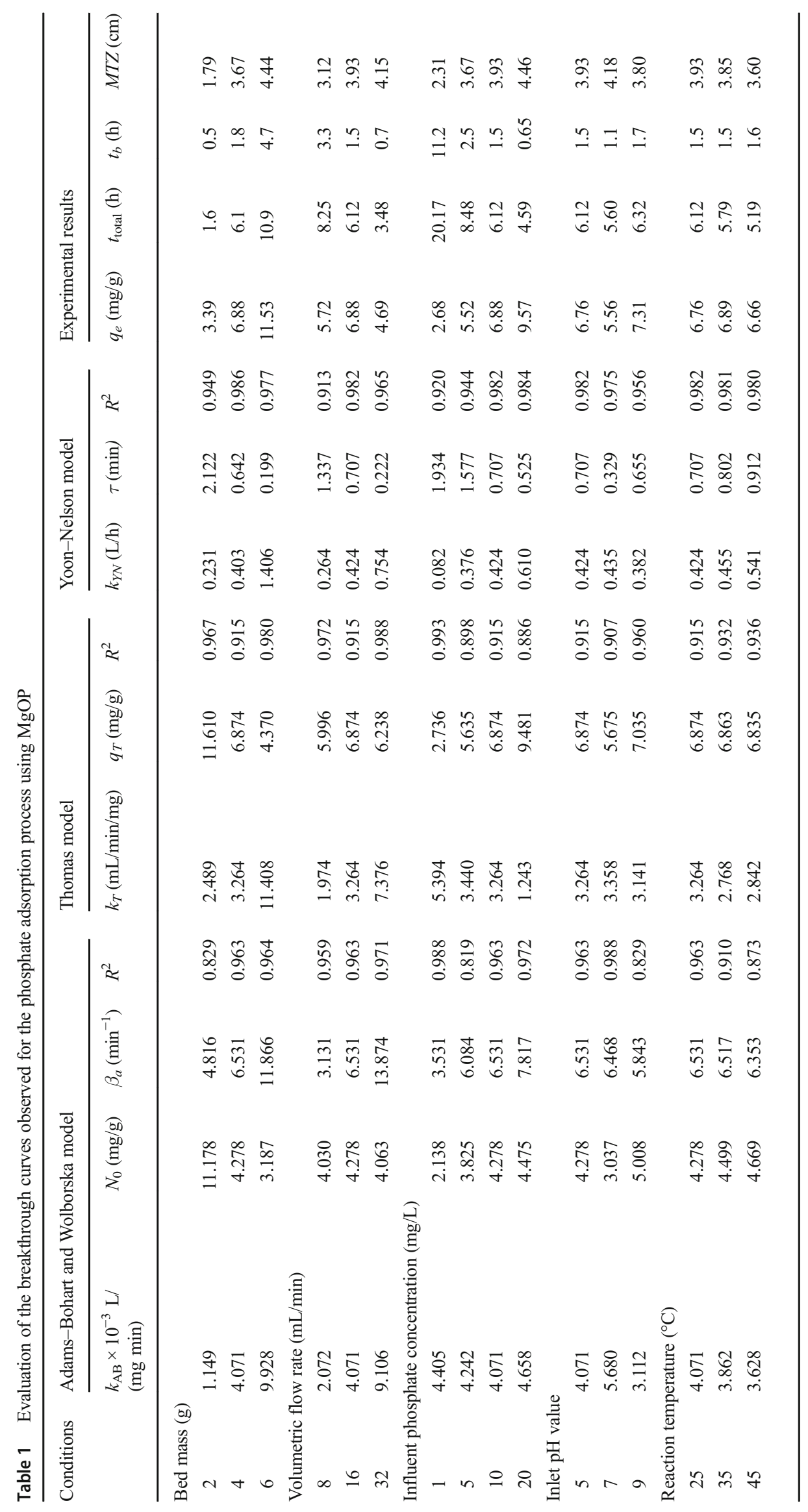




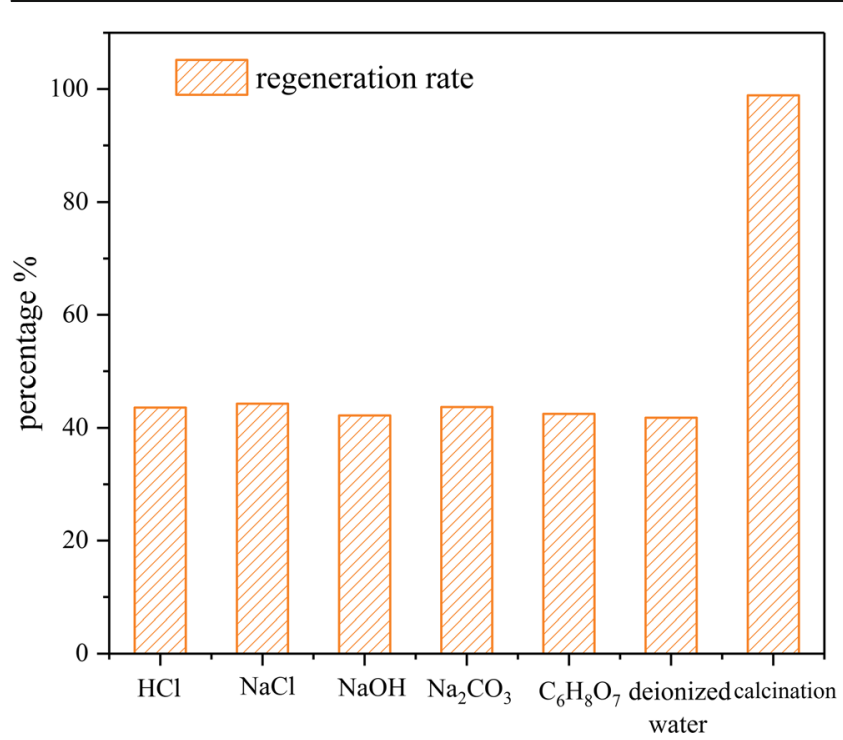

Fig. 7 The regeneration of $\mathrm{MgOP}$ using different methods. Conditions: $\mathrm{MgOP}$ concentration $=1.2 \mathrm{~g} / \mathrm{L}$, contact time $=100 \mathrm{~min}$, reaction temperature $=25^{\circ} \mathrm{C}$, and initial phosphate concentration $=10 \mathrm{mg} / \mathrm{L}$

used in the regeneration experiment can still adsorb additional phosphate ions. However, successful phosphate adsorption may not be attributed to the effective regeneration of the phosphate-adsorbed $\mathrm{MgOP}$, but to the hydroxyl groups that remained on the surface of the phosphate-adsorbed $\mathrm{MgOP}$ prior to regeneration. Hence, the regeneration experiment conducted in the presence of deionized water could be considered as a control experiment, which can be compared with the regeneration experiment conducted using the other solvents studied. The regeneration efficiency of the solvents other than deionized water used for the phosphate-adsorbed $\mathrm{MgOP}$ should subtract the regeneration efficiency achieved using deionized water $(\sim 50 \%)$. Hence, the regeneration efficiency of the solvents other than deionized water was low $(<1 \%)$ for the phosphate-loaded MgOP.

In contrast, the regeneration experiment conducted using the calcination of the phosphate-loaded $\mathrm{MgOP}$ at $450{ }^{\circ} \mathrm{C}$ presented an efficiency of $\sim 99 \%$. This may be attributed to the fact that fresh hydroxyl groups were formed on the surface of the calcined, phosphate-loaded MgOP. To explore the optimized calcination temperature and time used to regenerate the phosphate-loaded $\mathrm{MgOP}$, the phosphate-adsorbed $\mathrm{MgOP}$ was calcined at $100-550^{\circ} \mathrm{C}$ and the calcined time ranged from 15 to $90 \mathrm{~min}$. The results indicate that the optimized calcination temperature and time for the $\mathrm{MgOP}$ regeneration are $450{ }^{\circ} \mathrm{C}$ and $30 \mathrm{~min}$, respectively.

In addition, the MgOP regenerated via calcination was washed by doubly distilled water and then dried for the phosphate adsorption under the pre-determined conditions. After carrying out the regeneration experiments for six cycles, the regenerated $\mathrm{MgOP}$ still presents a high removal efficiency for phosphate (>95\%) (Fig. 7). It can be deduced that the phosphate removal process using $\mathrm{MgOP}$ was still efficient after multiple regeneration cycles.

\section{Conclusions}

The present study uses a MgOP composite for the effective separation of phosphates from an aqueous solution in batch and continuous systems. The results from the batch experiments demonstrate that the phosphate can be efficiently removed using $\mathrm{MgOP}$ over a wide range of $\mathrm{pH}$. In addition, co-existing anions exert negligible effects on the phosphate removal efficiency, which indicates the good affinity of $\mathrm{MgOP}$ for phosphate. Our study on the adsorption isotherms and kinetics indicates that the phosphate removal process using $\mathrm{MgOP}$ occurs via chemisorption. In conclusion, the mechanism of phosphate removal by MgOP mainly includes ligand exchange and hydrogen bonding. To guide the practical application of $\mathrm{MgOP}$ for phosphate removal in wastewater treatment, a fixed-bed column was used to study a continuous phosphate removal process using a synthetic solution, which can achieve the basic information required to upgrade the column in the future. An appropriate increase in the flow rate can facilitate the dynamic phosphate removal process. Moreover, both acidic and alkaline environments can improve phosphate adsorption on the MgOP bed. When compared with the other models, the dynamic adsorption capacity of phosphate estimated using the Thomas model was closest to the experimental values. Furthermore, the magnesium level in the treated water was found to be in the safe range for human health. The phosphate-adsorbed MgOP can be effectively regenerated via calcination and has a high adsorption capacity after multiple regeneration cycles. Overall, $\mathrm{MgOP}$ is a promising adsorbent for the effective and safe removal of phosphate from water on a plant scale.

Funding information This study is financially supported by the National Natural Science Foundation of China (51409108) and National Natural Science Foundation of China (21177045).

\section{References}

Aksu Z, Gönen F (2004) Biosorption of phenol by immobilized activated sludge in a continuous packed bed: prediction of breakthrough curves. Process Biochem 39:599-613

Arai Y, Sparks DL (2001) ATR-FTIR spectroscopic investigation on phosphate adsorption mechanisms at the ferrihydrite-water interface. J Colloid Interface Sci 241:317-326

Ashekuzzaman S, Jiang J-Q (2017) Strategic phosphate removal/ recovery by a re-usable $\mathrm{Mg}-\mathrm{Fe}-\mathrm{Cl}$ layered double hydroxide. Process Saf Environ Prot 107:454-462 
Belelli PG, Fuente SA, Castellani NJ (2014) Phosphate adsorption on goethite and Al-rich goethite. Comput Mater Sci 85:59-66

Bohart G, Adams E (1920) Some aspects of the behavior of charcoal with respect to chlorine. J Am Chem Soc 42:523-544

Borba C, Guirardello R, Silva E, Veit M, Tavares C (2006) Removal of nickel (II) ions from aqueous solution by biosorption in a fixed bed column: experimental and theoretical breakthrough curves. Biochem Eng J 30:184-191

Chatterjee S, Mondal S, De S (2017) Design and scaling up of fixed bed adsorption columns for lead removal by treated laterite. J Clean Prod 177:760-764

Chitrakar R, Tezuka S, Sonoda A, Sakane K, Ooi K, Hirotsu T (2006) Selective adsorption of phosphate from seawater and wastewater by amorphous zirconium hydroxide. J Colloid Interface Sci 297:426433

Chowdhury S, Saha PD (2013) Artificial neural network (ANN) modeling of adsorption of methylene blue by $\mathrm{NaOH}$-modified rice husk in a fixed-bed column system. Environ Sci Pollut Res 20:1050-1058

Du Z, Zheng T, Wang P (2018) Experimental and modelling studies on fixed bed adsorption for cu (II) removal from aqueous solution by carboxyl modified jute fiber. Powder Technol 338:952-959

Fathy M, Moghny TA, Mousa MA, El-Bellihi A-HA, Awadallah AE (2017) Synthesis of transparent amorphous carbon thin films from cellulose powder in Rice straw. Arab J Sci Eng 42:225-233

Guo X, Zeng L, Jin X (2013) Advanced regeneration and fixed-bed study of ammonium and potassium removal from anaerobic digested wastewater by natural zeolite. J Envion Sci 25:954-961

Guo-Mei C (2006) Ammonium molybdate spectrophotometric method for determination of total phosphorus in municipal sewage sludge [J]. China Water Wastewater 2:032

Hu T, Ding S, Deng H (2016) Application of three surface complexation models on U (VI) adsorption onto graphene oxide. Chem Eng J 289: 270-276

Hu P, Liu Q, Wang J, Huang R (2017) Phosphate removal by Ce(III)impregnated crosslinked chitosan complex from aqueous solutions. Polym Eng Sci 57:44-51

Huang J, Wu Z, Chen L, Sun Y (2015) Surface complexation modeling of adsorption of Cd (II) on graphene oxides. J Mol Liq 209:753-758

Huang W, Zhang Y, Li D (2017a) Adsorptive removal of phosphate from water using mesoporous materials: a review. J Environ Manag 193: 470-482

Huang W, Zhang Y, Li D (2017b) Adsorptive removal of phosphate from water using mesoporous materials: a review. J Environ Manage 193: 470-482

Jiang S, Wang X, Yang S, Shi H (2016) Characteristics of simultaneous ammonium and phosphate adsorption from hydrolysis urine onto natural loess. Environ Sci Pollut Res 23:2628-2639

Kang J, Bo L, Jing S, Li D, Jing Y, Wei Z, Liu D (2011) Defluoridation of water using calcined magnesia/pullulan composite. Chem Eng J 166:765-771

Kumar IA, Viswanathan N (2017) Development of multivalent metal ions imprinted chitosan biocomposites for phosphate sorption. Int J Biol Macromol 104:1539-1547

Lan W, Zhang J, Hu Z, Ji M, Zhang X, Zhang J, Li F, Yao G (2018) Phosphorus removal enhancement of magnesium modified constructed wetland microcosm and its mechanism study. Chem Eng J 335:209-214

Lee C, Jung J, Pawar RR, Kim M, Lee S-M (2017) Arsenate and phosphate removal from water using Fe-sericite composite beads in batch and fixed-bed systems. J Ind Eng Chem 47:375-383

Li R, Wang JJ, Zhou B, Zhang Z, Liu S, Lei S, Xiao R (2017) Simultaneous capture removal of phosphate, ammonium and organic substances by $\mathrm{MgO}$ impregnated biochar and its potential use in swine wastewater treatment. J Clean Prod 147:96-107
Lin J, Zhang Z, Zhan Y (2017) Effect of humic acid preloading on phosphate adsorption onto zirconium-modified zeolite. Environ Sci Pollut Res 24:12195-12211

Liu R, Chi L, Wang X, Sui Y, Wang Y, Arandiyan H (2018) Review of metal (hydr)oxide and other adsorptive materials for phosphate removal from water. J Environ Chem Eng 6(4):5269-5286

Loganathan P, Vigneswaran S, Kandasamy J, Naidu R (2013) Defluoridation of drinking water using adsorption processes. J Hazard Mater 248:1-19

Loganathan P, Vigneswaran S, Kandasamy J, Bolan NS (2014) Removal and recovery of phosphate from water using sorption. Crit Rev Environ Sci Technol 44:847-907

Mor S, Chhoden K, Ravindra K (2016) Application of agro-waste rice husk ash for the removal of phosphate from the wastewater. J Clean Prod 129:673-680

Muliwa AM, Leswifi TY, Maity A, Ochieng A, Onyango MS (2018) Fixed-bed operation for manganese removal from water using chitosan/bentonite/MnO composite beads. Environ Sci Pollut Res 25: 18081-18095

Nguyen T, Ngo H, Guo W, Pham T, Li F, Nguyen T, Bui X (2015) Adsorption of phosphate from aqueous solutions and sewage using zirconium loaded okara (ZLO): fixed-bed column study. Sci Total Environ 523:40-49

Nur T, Johir M, Loganathan P, Nguyen T, Vigneswaran S, Kandasamy J (2014) Phosphate removal from water using an iron oxide impregnated strong base anion exchange resin. J Ind Eng Chem 20:13011307

Shi S-L, Lv J-P, Liu Q, Nan F-R, Jiao X-Y, Feng J, Xie S-L (2018) Application of Phragmites australis to remove phenol from aqueous solutions by chemical activation in batch and fixed-bed columns. Environ Sci Pollut Res 25(24):23917-23928

Shi W, Fu Y, Jiang W, Ye Y, Kang J, Liu D, Ren Y, Li D, Luo C, Xu Z (2019) Enhanced phosphate removal by zeolite loaded with $\mathrm{Mg}$ Al-La ternary (hydr) oxides from aqueous solutions: performance and mechanism. Chem Eng J 357:33-44

Tang X, Wu M, Li R, Wang Z (2017) Prospect of recovering phosphorus in magnesium slag-packed wetland filter. Environ Sci Pollut Res 24: $22808-22815$

Tang X, Li R, Wu M, Dong L, Wang Z (2018) Enhanced phosphorus removal using acid-treated magnesium slag particles. Environ Sci Pollut Res 25:3860-3871

Tang Q, Shi C, Shi W, Huang X, Ye Y, Jiang W, Kang J, Liu D, Ren Y, Li D (2019) Preferable phosphate removal by nano-La (III) hydroxides modified mesoporous rice husk biochars: role of the host pore structure and point of zero charge. Sci Total Environ 662:511-520

Thomas HC (1944) Heterogeneous ion exchange in a flowing system. J Am Chem Soc 66:1664-1666

Uzunova EL, Mikosch H (2016) Adsorption of phosphates and phosphoric acid in zeolite clinoptilolite: electronic structure study. Microporous and Mesoporous Mater 232:119-125

Vieira ML, Pinheiro CP, Silva KA, Lutke SF, Cadaval TRSA, Dotto G, Pinto LADA (2019) Chitosan and cyanoguanidine-crosslinked chitosan coated glass beads and its application in fixed bed adsorption. Chem Eng Commun 1-13. https://doi.org/10.1080/00986445.2019. 1581618

Wan D, Liu H, Liu R, Qu J, Li S, Zhang J (2012) Adsorption of nitrate and nitrite from aqueous solution onto calcined $(\mathrm{Mg}-\mathrm{Al})$ hydrotalcite of different Mg/Al ratio. Chem Eng J 195:241-247

Wan S, Wang S, Li Y, Gao B (2017) Functionalizing biochar with Mg-Al and $\mathrm{Mg}-\mathrm{Fe}$ layered double hydroxides for removal of phosphate from aqueous solutions. J Ind Eng Chem 47:246-253

Wang Z, Nie E, Li J, Yang M, Zhao Y, Luo X, Zheng Z (2012) Equilibrium and kinetics of adsorption of phosphate onto irondoped activated carbon. Environ Sci Pollut Res 19:2908-2917

Willis J (1961) Determination of calcium and magnesium in urine by atomic absorption spectroscopy. Anal Chem 33:556-559 
Wolborska A (1989) Adsorption on activated carbon of p-nitrophenol from aqueous solution. Water Res 23:85-91

Xia T, Wang Y (2014) Dynamic experiment of modified rice husk adsorb methylene blue. Environ Sci Technol 37:417

Xu Z, Cai J-g, Pan B-c (2013) Mathematically modeling fixed-bed adsorption in aqueous systems. J Zhejiang Univ SCI A 14:155-176

Xu R, Zhang M, Mortimer RJ, Pan G (2017) Enhanced phosphorus locking by novel lanthanum/aluminum-hydroxide composite: implications for eutrophication control. Environ Sci Technol 51:34183425

Ye Y, Hu Y, Hussain Z, Li X, Li D, Kang J (2016a) Simultaneous adsorptive removal of fluoride and phosphate by magnesia-pullulan composite from aqueous solution. RSC Adv 6:35966-35976

Ye Y, Ngo HH, Guo W, Liu Y, Zhang X, Guo J, B-j N, Chang SW, Nguyen DD (2016b) Insight into biological phosphate recovery from sewage. Bioresour Technol 218:874-881

Ye Y, Ngo HH, Guo W, Liu Y, Li J, Liu Y, Zhang X, Jia H (2017) Insight into chemical phosphate recovery from municipal wastewater. Sci Total Environ 576:159-171

Ye Y, Liu W, Jiang W, Kang J, Ngo HH, Guo W, Liu Y (2018a) Defluoridation by magnesia-pullulan: surface complexation modeling and $\mathrm{pH}$ neutralization of treated fluoride water by aluminum. J Taiwan Inst Chem E 93:625-631

Ye Y, Yang J, Jiang W, Kang J, Hu Y, Ngo HH, Guo W, Liu Y (2018b) Fluoride removal from water using a magnesia-pullulan composite in a continuous fixed-bed column. J Environ Manag 206:929-937
Yoon YH, Nelson J (1984) Application of gas adsorption kinetics I. A theoretical model for respirator cartridge service life. Am Ind Hyg Assoc J 45:509-516

Zhang G, Liu H, Liu R, Qu J (2009) Removal of phosphate from water by a Fe-Mn binary oxide adsorbent. J Colloid Interface Sci 335:168174

Zhang J, Shen Z, Shan W, Chen Z, Mei Z, Lei Y, Wang W (2010) Adsorption behavior of phosphate on lanthanum (III) doped mesoporous silicates material. J Envion Sci 22:507-511

Zhang B, Chen N, Feng C, Zhang Z (2018) Adsorption for phosphate by crosslinked/non-crosslinked-chitosan-Fe (III) complex sorbents: characteristic and mechanism. Chem Eng J 353:361-372

Zhu Z, Zeng H, Zhu Y, Yang F, Zhu H, Qin H, Wei W (2013) Kinetics and thermodynamic study of phosphate adsorption on the porous biomorph-genetic composite of $\alpha$-Fe2O3/Fe3O4/C with eucalyptus wood microstructure. Sep Purif Technol 117:124-130

Publisher's note Springer Nature remains neutral with regard to jurisdictional claims in published maps and institutional affiliations. 